\title{
Research Paper: Feasibility, Satisfaction With, and Attitude Toward Telerehabilitation During COVID-19 Pandemic: Experience of Iranian Rehabilitation Professionals
}

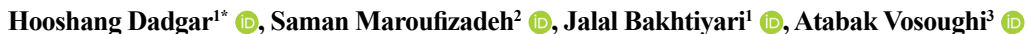

1. Department of Speech Therapy, School of Rehabilitation, Tehran University of Medical Sciences, Tehran, Iran.

2. Department of Biostatistics, School of Nursing and Midwifery, Guilan University of Medical Sciences, Rasht, Iran.

3. CEO Zehn-e-Ziba Rehabilitation Clinic, Tehran, Iran.

\begin{tabular}{|c|c|}
\hline $\begin{array}{l}\text { Use your device to scan } \\
\text { and read the article online }\end{array}$ & ditation Dadgar H, Maroufizadeh S, Bakhtiyari J, Vosoughi A. Feasibility, Satisfaction With, and Attitude Toward Telere- \\
\hline 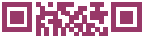 & habilitation During COVID-19 Pandemic: Experience of Iranian Rehabilitation Professionals. Iranian Rehabilitation Journal. \\
\hline 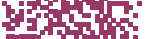 & 2021; 19(4):399-406. http://dx.doi.org/10.32598/irj.19.4.1491.1 \\
\hline 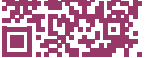 & dol'http://dx.doi.org/10.32598/irj.19.4.1491.1 \\
\hline
\end{tabular}

Article info:

Received: 31 May 2021

Accepted: 20 Sep 2021

Available Online: 01 Dec 2021

Keywords:

Rehabilitation, Telerehabilitation, Telemedicine, COVID-19,

Pandemic

\section{A B S T RACT}

Objectives: COVID-19 pandemic and its consequences highlighted the importance of using telerehabilitation systems and affected the professional's attitude toward it. This study aimed to investigate the feasibility, satisfaction, and attitude of rehabilitation professionals toward telerehabilitation during the COVID-19 pandemic in Iran.

Methods: Aweb-based cross-sectional study was conducted to assess the feasibility, satisfaction, and attitude of rehabilitation professionals toward virtual training and telerehabilitation during the COVID-19 pandemic. A total of 118 occupational therapists, speech therapists, audiologists, psychologists, and educators completed the study questionnaires.

Results: The findings indicate that the correlations among satisfaction, feasibility, advantages, and compatibility were significant ( $\mathrm{r}$ ranging from 0.418 to 0.717 ). There were significant but weak positive correlations between years of working experience and scores of feasibility and advantages. In addition, the mean scores of feasibility, advantages, compatibility, and complexity in participants who provided telerehabilitation before the COVID-19 pandemic were higher than other respondents.

Discussion: Because of the positive role of telerehabilitation in a situation such as the COVID-19 pandemic, health care systems should create mechanisms for its optimal use, protocol preparation, health professionals training, and infrastructure acquisition. 


\section{Highlights}

- The present study's correlations among satisfaction, feasibility, advantages, and compatibility were significant.

- The feasibility of telehealth systems can increase the number of intervention sessions per week among professionals.

- The mean level of satisfaction was also higher in rehabilitation professionals who provided telerehabilitation before the COVID-19 pandemic.

\section{Plain Language Summary}

Would you please provide a Plain Language Summary for the article in 200-300 words? Consider that Plain Language Summary is different from abstract, and it has to be written for non-specialists. To provide it, consider the following points: 1. think about your audience (e.g., journalists, science-interested public), 2. Get rid of jargon, 3. Explain what the study is about. Remember, others will need more context about what you studied, 4. Explain what you found, 5. Explain why this matters. Discuss the importance of these findings not just in terms of their implications for your field but in terms of their relevance to the public.

\section{Introduction}

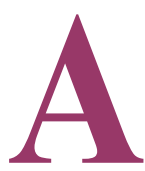

ccording to the definition of the World Health Organization (WHO), telerehabilitation is the provision of diagnostic, therapeutic, and preventive services using communication technologies by all health care professionals from a distance [1]. Based on this definition, other terms such as telemedicine, ehealth, and telecare have been used interchangeably with telerehabilitation in the literature. Telerehabilitation uses various technologies such as mobile applications, video conferencing, and web applications [2]. The role of telerehabilitation and telemedicine in health systems has received increased attention across many disciplines. For example, different branches of telerehabilitation such as telepsychiatry, telerehabilitation, and telepsychology have provided services with this method in recent years [3].

Previous studies have examined the effectiveness and the possible advantages of telerehabilitation. In a metaanalysis by Wootton [4], most studies reported the positive effect of telemedicine in managing chronic diseases, and only two studies reported adverse effects. Improving access for patients, particularly patients in rural areas, and cost-effectiveness are the most important advantages of telerehabilitation $[5,6]$. Although limited studies have examined its effectiveness between two healthcare services, telerehabilitation seems more helpful to patients with disabilities because they have more transfer problems [7, 8].

The extent and effective implementation of telerehabilitation by professionals depends on several factors, such as their attitudes toward it and digital infrastructures [9, 10]. However, the attitudes toward the use of telerehabilitation in recent decades may have changed due to the rapid technological changes and the positive results reported in studies.

All countries in the world have been affected by a novel coronavirus (COVID-19) which has changed many of the common rules of life. Many countries have imposed various restrictions, such as reducing travel, social distance, and quarantine to reduce the pandemic [11]. Following the coronavirus pandemic, the tendency to use technology such as virtualization increased to reduce the effects of restrictions. However, the unpreparedness of some countries, such as Italy, to use these services was highlighted during the coronavirus pandemic [12]. It now appears that the coronavirus pandemic will also affect the attitude towards using telerehabilitation in the world [13].

After the pandemic and implementing some restrictions to control it, rehabilitation specialists In Iran used telerehabilitation services to train and follow-up intervention. Based on the extensive use of telerehabilitation and virtual training in the coronavirus pandemic and considering the advantages of this method, this study aimed to investigate the feasibility and satisfaction with and attitudes toward telerehabilitation services among rehabilitation professionals.

\section{Materials and Methods}

A web-based cross-sectional study was conducted to assess the feasibility, satisfaction, and attitude of rehabil- 
itation professionals toward virtual training and telerehabilitation in the COVID-19 pandemic. First, a questionnaire was designed and modified based on previous studies and literature review [14-17]. This research-made questionnaire includes 27 questions, categorized into four sections: demographic information [2], satisfaction [3], feasibility, and [4] attitude toward telerehabilitation. The attitude section includes the sub-sections of advantages, compatibility, and complexity. The questions were scored on a 5-point Likert scale ranging from 1= "strongly agree" to 5="strongly disagree." The questionnaire was reviewed by an expert panel comprising two speech therapists, one occupational therapist, one psychologist, and one linguist. Content validity was evaluated using the content validity ratio (CVR) and content validity index (CVI) based on Lawshe's model. The expert panel was asked to rate the appropriateness of questionnaire items using a 3-point scale (essential=1, useful but not necessary $=2$, and not necessary $=3$ ). To determine CVI, panel members rated items based on its clarity and its relevancy. CVR and CVI were considered 0.99 that is an acceptable level for the questionnaire. Finally, the online form of the questionnaire was prepared. An online questionnaire link was sent to five groups of specialists, including occupational therapists, speech therapists, audiologists, psychologists, and educators. This study was conducted anonymously during March and April 2020, and 118 individuals completed the questionnaires.

\section{Statistical analysis}

In this study, continuous variables were expressed as Mean \pm SD and categorical variables as frequency (\%). The Kolmogorov-Smirnov test was used to examine the normality of data, and the hypothesis of normality was rejected for all study variables $(\mathrm{P}<0.05)$. Correlational analyses were performed to explore the relationship among study variables. In addition, the Spearman correlation coefficient, Mann-Whitney test, and KruskalWallis test were conducted to examine the relationship between study variables and demographic/COVID19-related variables. Data analysis was performed using SPSS for Windows, version 16 (SPSS Inc., Chicago, IL, USA), and the level of significance was set at 0.05 .

\section{Results}

\section{Participant's characteristics}

The demographic and COVID-19-related variables of the respondents are outlined in Table 1. The Mean \pm SD age of the respondents was $36.89 \pm 8.63$ years, and their Mean \pm SD working experience was $12.03 \pm 8.20$ years.
Of the respondents, $73.5 \%$ were female, $11.1 \%$ had a $\mathrm{PhD}, 47.9 \%$ had MSc, and $41 \%$ had BSc. In addition, $59.8 \%$ of them had not used telerehabilitation services before the virus pandemic.

\section{Correlations between study variables}

Table 2 presents correlations among study variables. The findings indicate that the correlations among satisfaction, feasibility, advantages, and compatibility were significant ( $\mathrm{r}$ ranging from 0.418 to 0.717 ), whereas complexity was not correlated with satisfaction, feasibility, advantages, and compatibility.

Relationships between demographic/COVID-19 related variables and study variables

There were significant but low positive correlations between age and feasibility and advantages $(r=0.197$ and $\mathrm{r}=0.182$, respectively). The same results were found for working experience. The session duration was also positively correlated with satisfaction and compatibility $(r=0.269$ and $\mathrm{r}=0.216$, respectively). There was a direct relationship between the number of sessions per week and feasibility $(\mathrm{P}=0.005)$. Mean scores of feasibility, advantages, compatibility, and complexity in participants who provided telerehabilitation before the COVID-19 pandemic were higher than other participants. The mean level of satisfaction was also higher in participants who provided telerehabilitation before the COVID-19 pandemic, although this difference was not statistically significant $(\mathrm{P}=0.104)$. The use of telerehabilitation during the COVID-19 pandemic was also related to satisfaction and feasibility scores $(\mathrm{P}=0.005$ and $\mathrm{P}=0.003$, respectively) (Table 3 ).

\section{Discussion}

The use of new technologies such as telerehabilitation in health care systems is influenced by various factors that have been investigated in previous studies. Recently, with the COVID-19 pandemic, the importance and the need to use these systems have been highlighted more than ever. This study provides evidence of experience and attitudes toward telerehabilitation delivery systems among rehabilitation professionals during the COVID-19 pandemic.

This study shows that the number of respondents in the audiologist group was low compared to other disciplines, which could be due to the difference in the nature of their work as it is instrument-based work. 
Table 1. Demographic and COVID-9-related variables among participants

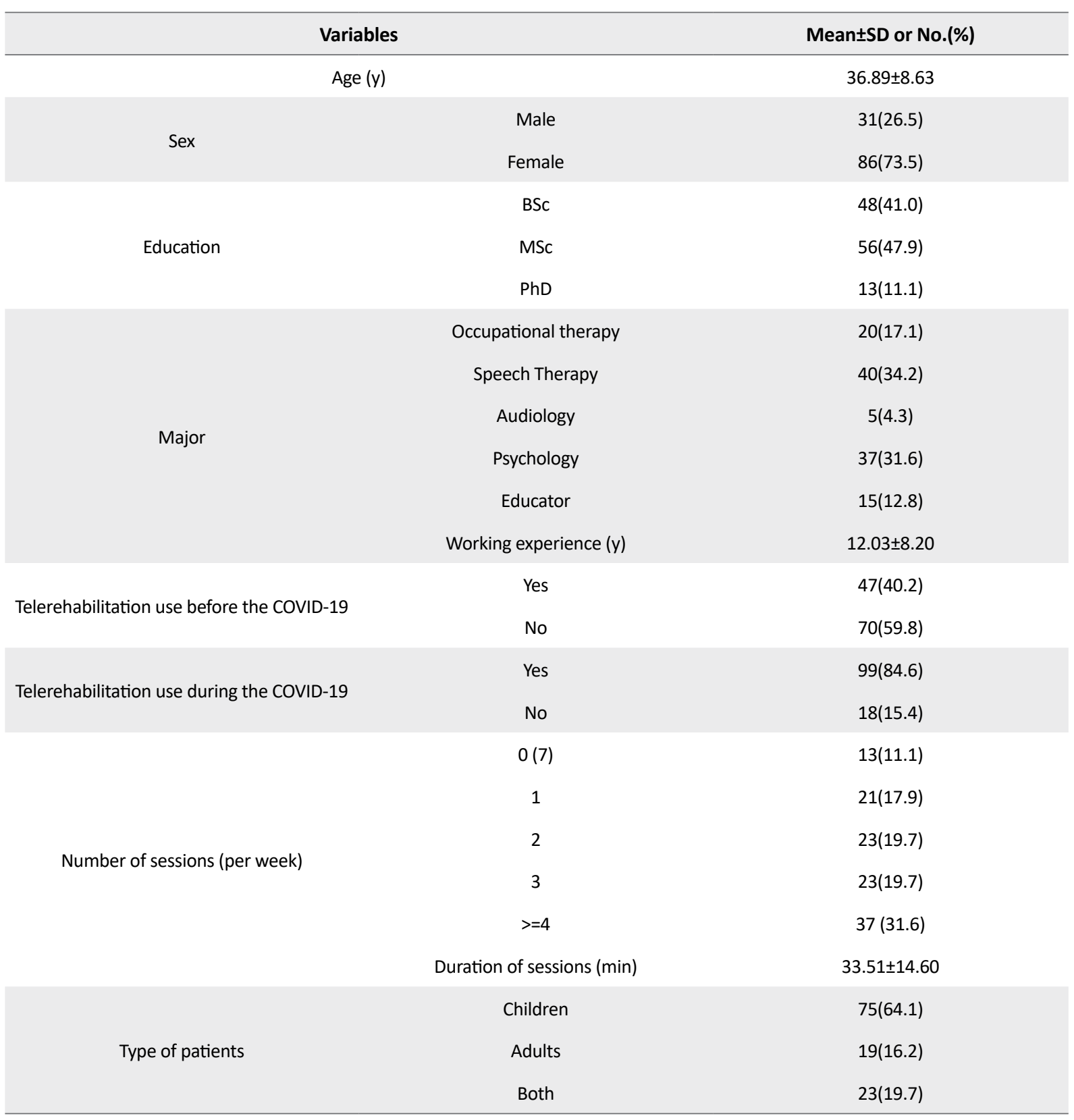

Пranian Rehabilitation \ournal

Table 2. Correlations between study variables

\begin{tabular}{ccccccc}
\hline Variables & Mean \pm SD & $\mathbf{1}$ & $\mathbf{2}$ & $\mathbf{3}$ & $\mathbf{4}$ & $\mathbf{5}$ \\
\hline 1 Satisfaction & $2.94 \pm 0.78$ & 1 & & & \\
2 Feasibility & $3.04 \pm 0.83$ & $0.671^{* * *}$ & 1 & & & \\
3 Advantages & $3.22 \pm 0.88$ & $0.642^{* * *}$ & $0.541^{* * *}$ & 1 & & \\
\hline 4 Compatibility & $3.15 \pm 0.92$ & $0.585^{* * *}$ & $0.418^{* * *}$ & $0.717^{* * *}$ & 1 & \\
\hline 5 Complexity & $3.33 \pm 0.67$ & 0.018 & 0.050 & -0.030 & -0.077 & 1 \\
\hline
\end{tabular}

*** $\mathrm{P}<0.001$

Пranian Rehabilltation \ournal 
Table 3. Relationship of demographic and COVID-19-related characteristics with study variables

\begin{tabular}{|c|c|c|c|c|c|c|c|c|c|c|}
\hline \multirow{2}{*}{ Variables } & \multicolumn{10}{|c|}{ Mean $\pm S D$ or } \\
\hline & $\begin{array}{c}\text { Satisfac- } \\
\text { tion }\end{array}$ & $\mathbf{P}$ & Feasibility & $\mathbf{P}$ & $\begin{array}{c}\text { Advan- } \\
\text { tages }\end{array}$ & $\mathbf{P}$ & $\begin{array}{l}\text { Compat- } \\
\text { ibility }\end{array}$ & $\mathbf{P}$ & $\begin{array}{l}\text { Complex- } \\
\text { ity }\end{array}$ & $\mathbf{P}$ \\
\hline Age (y & 0.093 & 0.317 & 0.197 & 0.033 & 0.182 & 0.049 & 0.115 & 0.216 & 0.075 & 0.422 \\
\hline Sex & & 0.654 & & 0.414 & & 0.390 & & 0.693 & & 0.720 \\
\hline Male & $3.01 \pm 0.86$ & & $3.11 \pm 0.85$ & & $3.34 \pm 0.73$ & & $3.19 \pm 0.83$ & & $3.27 \pm 0.67$ & \\
\hline Female & $2.91 \pm 0.75$ & & $3.02 \pm 0.83$ & & $3.18 \pm 0.92$ & & $3.13 \pm 0.96$ & & $3.35 \pm 0.67$ & \\
\hline Education & & 0.842 & & 0.972 & & 0.704 & & 0.192 & & 0.853 \\
\hline $\mathrm{BSC}$ & $3.04 \pm 0.67$ & & $3.12 \pm 0.68$ & & $3.30 \pm 0.81$ & & $3.33 \pm 0.88$ & & $3.31 \pm 0.67$ & \\
\hline MSc & $2.85 \pm 0.91$ & & $2.96 \pm 0.99$ & & $3.12 \pm 0.97$ & & $2.98 \pm 1.01$ & & $3.36 \pm 0.67$ & \\
\hline $\mathrm{PhD}$ & $2.94 \pm 0.44$ & & $3.08 \pm 0.57$ & & $3.38 \pm 0.62$ & & $3.15 \pm 0.43$ & & $3.29 \pm 0.73$ & \\
\hline Major & & 0.856 & & 0.229 & & 0.500 & & 0.394 & & 0.923 \\
\hline Occupational therapy & $2.86 \pm 0.64$ & & $2.98 \pm 0.79$ & & $3.25 \pm 0.75$ & & $2.88 \pm 0.78$ & & $3.34 \pm 0.60$ & \\
\hline Speech Therapy & $3.00 \pm 0.92$ & & $3.21 \pm 0.95$ & & $3.36 \pm 0.82$ & & $3.29 \pm 0.99$ & & $3.21 \pm 0.81$ & \\
\hline Audiology & $3.24 \pm 1.01$ & & $3.30 \pm 0.91$ & & $3.60 \pm 0.52$ & & $3.40 \pm 0.65$ & & $3.55 \pm 0.27$ & \\
\hline Psychology & $2.91 \pm 0.73$ & & $2.95 \pm 0.73$ & & $3.12 \pm 0.92$ & & $3.15 \pm 0.86$ & & $3.39 \pm 0.57$ & \\
\hline Instructor & $2.84 \pm 0.62$ & & $2.83 \pm 0.75$ & & $2.95 \pm 1.11$ & & $3.03 \pm 1.13$ & & $3.42 \pm 0.67$ & \\
\hline Working experience $\pm y$ & 0.109 & 0.241 & 0.216 & 0.019 & 0.242 & 0.009 & 0.104 & 0.266 & 0.031 & 0.738 \\
\hline $\begin{array}{l}\text { Telerehabilitation use } \\
\text { before the COVID-19 }\end{array}$ & & 0.104 & & 0.005 & & $<0.001$ & & 0.030 & & 0.029 \\
\hline Yes & $3.11 \pm 0.58$ & & $3.33 \pm 0.68$ & & $3.58 \pm 0.63$ & & $3.39 \pm 0.77$ & & $3.48 \pm 0.63$ & \\
\hline No & $2.83 \pm 0.87$ & & $2.85 \pm 0.87$ & & $2.98 \pm 0.94$ & & $2.98 \pm 0.98$ & & $3.22 \pm 0.68$ & \\
\hline $\begin{array}{l}\text { Telerehabilitation use } \\
\text { during the COVID-19 }\end{array}$ & & 0.005 & & 0.003 & & 0.191 & & 0.495 & & 0.350 \\
\hline Yes & $3.05 \pm 0.71$ & & $3.16 \pm 0.76$ & & $3.28 \pm 0.84$ & & $3.18 \pm 0.88$ & & $3.36 \pm 0.65$ & \\
\hline No & $2.34 \pm 0.88$ & & $2.42 \pm 0.96$ & & $2.89 \pm 1.02$ & & $2.94 \pm 1.11$ & & $3.17 \pm 0.75$ & \\
\hline $\begin{array}{c}\text { Number of } \\
\text { sessions } \pm \text { per week }\end{array}$ & & 0.061 & & 0.005 & & 0.132 & & 0.263 & & 0.256 \\
\hline $0 \pm 7$ & $2.15 \pm 0.95$ & & $2.08 \pm 0.89$ & & $2.79 \pm 1.01$ & & $2.69 \pm 1.13$ & & $3.08 \pm 0.79$ & \\
\hline 1 & $3.03 \pm 0.59$ & & $3.17 \pm 0.56$ & & $3.37 \pm 0.80$ & & $3.12 \pm 1.00$ & & $3.11 \pm 0.77$ & \\
\hline 2 & $3.06 \pm 0.86$ & & $3.11 \pm 0.88$ & & $3.00 \pm 0.85$ & & $2.98 \pm 0.89$ & & $3.35 \pm 0.63$ & \\
\hline 3 & $2.98 \pm 0.64$ & & $3.22 \pm 0.80$ & & $3.50 \pm 0.81$ & & $3.41 \pm 0.91$ & & $3.43 \pm 0.71$ & \\
\hline$>=4$ & $3.06 \pm 0.70$ & & $3.16 \pm 0.75$ & & $3.26 \pm 0.88$ & & $3.26 \pm 0.79$ & & $3.47 \pm 0.53$ & \\
\hline $\begin{array}{c}\text { Duration of } \\
\text { sessions } \pm \text { minutes }\end{array}$ & 0.269 & 0.006 & 0.130 & 0.190 & 0.176 & 0.074 & 0.216 & 0.028 & 0.067 & 0.502 \\
\hline Type of patients & & 0.805 & & 0.942 & & 0.513 & & 0.618 & & 0.578 \\
\hline Children & $2.93 \pm 0.78$ & & $3.03 \pm 0.81$ & & $3.22 \pm 0.87$ & & $3.10 \pm 0.96$ & & $3.26 \pm 0.73$ & \\
\hline Adults & $2.89 \pm 0.76$ & & $3.00 \pm 0.85$ & & $3.32 \pm 0.97$ & & $3.21 \pm 0.95$ & & $3.34 \pm 0.55$ & \\
\hline Both & $3.00 \pm 0.80$ & & $3.11 \pm 0.93$ & & $3.15 \pm 0.84$ & & $3.24 \pm 0.78$ & & $3.53 \pm 0.52$ & \\
\hline
\end{tabular}

r: the Spearman correlation coefficient.

Пranian Rehabilitation \ourna 
The study findings showed that all disciplines were positively satisfied with the telerehabilitation and rated its' feasibility as moderate. Previous studies have reported a variety of satisfaction rates among health professionals. For example, Richards et al. demonstrated positive satisfaction with using telemedicine among clinicians [18]. However, Krousel-Wood et al. and Krousel-Wood, Re [18] reported physicians' workload and stress increase during telemedicine compared to faceto-face visits [19]. These differences can be due to the differences in technologies used in telemedicine, as well as the variety of health professionals' fields.

The feasibility of telerehabilitation systems determines success as well as the percentage of usage. In this study, there were positive correlations between feasibility and work experience with the number of sessions used per week. Similar to our results, Sargeant, Allen [20] showed that physicians' positive attitudes toward telemedicine were significantly correlated with the number of telemedicine sessions.

Interestingly, the results of this study showed a positive correlation between having experience with telerehabilitation before the COVID-19 pandemic and variables of feasibility, advantages, compatibility, and complexity. Similar to our results, Barton et al. reported significant differences between users and nonusers of telemedicine in attitudes toward telemedicine [21]. All specialty professionals had a generally positive attitude toward telemedicine in the current study. A search of the literature revealed few studies which examined the attitude of rehabilitation professionals toward telerehabilitation. Tucker (2012) conducted a study among 170 schoolbased speech-language pathologists. He examined the perspectives of speech and language pathologists on the use of telepractice in schools. He showed that respondents disagreed with its validity and effectiveness [22]. However, a recent systematic literature review concluded that the attitude of audiologists toward telerehabilitation is positive [23].

Although the COVID-19 pandemic is influential in using telerehabilitation, further assessment is needed to determine the effect of factors such as infrastructure and cultural issues. Besides, because of the positive role of telerehabilitation in a situation such as the COVID-19 pandemic, health care systems should plan on creating mechanisms for its optimal use, protocol preparation, health professionals training, and infrastructure acquisition. Our study has some limitations. The study's main limitation was the unequal number of participants in different disciplines, which limits the generalizability of the findings. On the other hand, we did not focus on a specific disorder and its feasibility of telerehabilitation may vary for different disorders.

\section{Conclusion}

According to the present study results, telerehabilitation is feasible, and the user had satisfaction with this method. Therefore, as a valuable method, it requires health professionals' training and infrastructure acquisition.

\section{Ethical Considerations}

\section{Compliance with ethical guidelines}

There were no ethical considerations to be considered in this research.

\section{Funding}

This research did not receive any grant from funding agencies in the public, commercial, or non-profit sectors.

\section{Authors' contributions}

All authors equally contributed to preparing this article.

\section{Conflict of interest}

The authors declared no conflict of interest.

\section{References}

[1] Ryu S. Telemedicine: Opportunities and developments in member states: Report on the second global survey on eHealth 2009 (global observatory for eHealth series, volume 2). Healthcare Informatics Research. 2012; 18(2):153-5. [DOI:10.4258/hir.2012.18.2.153]

[2] Albarrak AI, Mohammed R, Almarshoud N, Almujalli L, Aljaeed R, Altuwaijiri S, et al. Assessment of physician's knowledge, perception and willingness of telemedicine in Riyadh region, Saudi Arabia. Journal of Infection and Public Health. 2021; 14(1):97-102. [DOI:10.1016/j.jiph.2019.04.006]

[3] WHO. Telemedicine: Opportunities and developments in member states: Report on the second global survey on eHealth. Geneva: World Health Organization; 2010. https:/ / apps.who.int/iris/handle/10665/44497

[4] Wootton R. Twenty years of telemedicine in chronic disease management-an evidence synthesis. Journal of Telemedicine and Telecare. 2012; 18(4):211-20. [DOI:10.1258/ jtt.2012.120219] [PMID] [PMCID] 
[5] Laver KE, Adey-Wakeling Z, Crotty M, Lannin NA George S, Sherrington C. Telerehabilitation services for stroke. Cochrane Database of Systematic Reviews. 2020; 1(1):CD010255. [PMID] [PMCID]

[DOI:10.1002/14651858.CD010255.pub3]

[6] Moffatt JJ, Eley DS. The reported benefits of telehealth for rural Australians. Australian Health Review. 2010; 34(3):276-81. [DOI:10.1071/AH09794] [PMID]

[7] Rabanifar N, Abdi K. Rehabilitation services: Why should we use tele-rehabilitation in Iran? Necessity and application. Iranian Rehabilitation Journal. 2019; 17(4):293-6. [DOI:10.32598/ irj.17.4.293]

[8] Torsney K. Advantages and disadvantages of telerehabilitation for persons with neurological disabilities. NeuroRehabilitation. 2003; 18(2):183-5. [PMID]

[9] Nazviya M, Kodukula S. Evaluation of critical success factors for telemedicine implementation. International Journal of Computer Applications. 2011; 12(10):29-36. [DOI:10.5120/1718-2304]

[10] Olok GT, Yagos WO, Ovuga E. Knowledge and attitudes of doctors towards e-health use in healthcare delivery in government and private hospitals in Northern Uganda: A cross-sectional study. BMC Medical Informatics and Decision Making. 2015; 15:87. [DOI:10.1186/s12911-015-0209-8] [PMID] [PMCID]

[11] Wilder-Smith A, Freedman DO. Isolation, quarantine, social distancing and community containment: Pivotal role for old-style public health measures in the novel coronavirus (2019-nCoV) outbreak. Journal of Travel Medicine. 2020; 27(2):taaa020. [DOI:10.1093/jtm/taaa020] [PMID] [PMCID]

[12] Omboni S. Telemedicine during the COVID-19 in Italy: A missed opportunity? Telemedicine Journal and e-Health. 2020; 26(8):973-5. [DOI:10.1089/tmj.2020.0106] [PMID] [PMCID]

[13] Rabanifar N, Abdi K. Letter to Editor: Telerehabilitation: A Useful and appropriate approach for people with disability in Covid-19 pandemic. Medical Journal of the Islamic Republic of Iran. 2021; 35:18. [DOI:10.47176/mjiri.35.18] [PMID] [PMCID]

[14] Biruk K, Abetu E. Knowledge and attitude of health professionals toward telemedicine in resource-limited settings: A cross-sectional study in North West Ethiopia. Journal of Healthcare Engineering. 2018; 2018:2389268. [DOI:10.1155/2018/2389268] [PMID] [PMCID]

[15] Keshvari H, Haddadpoor A, Taheri B, Nasri M. Determining the awareness and attitude of employees in Deputy of Health of Isfahan University of Medical Science toward telemedicine and its advantages. Acta Informatica Medica. 2015; 23(2):97-101. [DOI:10.5455/aim.2015.23.97-101] [PMID] [PMCID]

[16] Morgan DG, Kosteniuk J, Stewart N, O'connell ME, Karunanayake C, Beever R. The telehealth satisfaction scale: Reliability, validity, and satisfaction with telehealth in a rural memory clinic population. Telemedicine and e-Health. 2014; 20(11):997-1003. [DOI:10.1089/tmj.2014.0002] [PMID] [PMCID]

[17] Zayapragassarazan Z, Kumar S. Awareness, knowledge, attitude and skills of telemedicine among health professional faculty working in teaching hospitals. Journal of Clinical and Diagnostic Research: Journal of Clinical and Diagnostic Research. 2016; 10(3):JC01-4. [DOI:10.7860/ JCDR/2016/19080.7431] [PMID] [PMCID]
[18] Richards H, King G, Reid M, Selvaraj S, McNicol I, Brebner E, et al. Remote working: Survey of attitudes to eHealth of doctors and nurses in rural general practices in the United Kingdom. Family Practice. 2005; 22(1):2-7. [DOI:10.1093/fampra/cmh716] [PMID]

[19] Krousel-Wood MA, Re RN, Abdoh A, Bradford D, Kleit A Chambers R, et al. Patient and physician satisfaction in a clinical study of telemedicine in a hypertensive patient population. Journal of Telemedicine and Telecare. 2001; 7(4):206-11. [DOI:10.1258/1357633011936417] [PMID]

[20] Sargeant J, Allen M, Langille D. Physician perceptions of the effect of telemedicine on rural retention and recruitment. Journal of Telemedicine and Telecare. 2004; 10(2):89-93. [DOI: 10.1258/135763304773391521] [PMID]

[21] Barton PL, Brega AG, Devore PA, Mueller K, Paulich MJ, Floersch NR, et al. Specialist physicians' knowledge and beliefs about telemedicine: A comparison of users and nonusers of the technology. Telemedicine Journal and e-Health. 2007; 13(5):487-99. [DOI:10.1089/tmj.2006.0091] [PMID]

[22] Tucker JK. Perspectives of speech-language pathologists on the use of telepractice in schools: The qualitative view. International journal of Telerehabilitation. 2012; 4(2):47-60. [DOI:10.5195/ijt.2012.6102]

[23] Ravi R, Gunjawate DR, Yerraguntla K, Driscoll C. Knowledge and perceptions of teleaudiology among audiologists: A systematic review. Journal of Audiology \& Otology. 2018; 22(3):120-7. [DOI:10.7874/jao.2017.00353] [PMID] [PMCID] 
This Page Intentionally Left Blank 